\title{
Sıcak Pres ile Üretilmiş Al-Nano SiC Kompozitin Mekanik Özelliklerinin İncelenmesi
}

\author{
Rıdvan YAMANOĞLU*1 (D), Erdinç EFENDİ² (D)
}

${ }^{1}$ Kocaeli Üniversitesi, Mühendislik Fakültesi, Metalurji ve Malzeme Mühendisliği Bölümü, 41380, Kocaeli, Türkiye

${ }^{2}$ Kocaeli Üniversitesi, Mühendislik Fakültesi, Makine Mühendisliği Bölümü, 41380, Kocaeli, Türkiye

(Alınıș / Received: 16.02.2019, Kabul / Accepted: 31.07.2019, Online Yayınlanma / Published Online: 30.08.2019)

Anahtar Kelimeler

Nano SiC,

Kompozit,

Sicak pres,

Sinterleme
Özet: Bu çalışmada saf alüminyum (Al) matris içerisine ağırlıkça $\% 0.25,0.5$ ve 1 oranlarında nano silisyum karbür partikülleri ilave edilmiş ve ardından toz karışımları önce mekanik alaşımlama, daha sonra sıcak pres ile sinterleme işlemine tabi tutulmuştur. Sinterleme sonrasında elde edilen numuneler metalografik ișlemler ile hazırlanıp aşınma ve eğilme testlerine tabi tutulmuștur. Aşınma testleri sonucunda, saf Al matrise artan miktarda nanopartikül ilavesinin, belli orana kadar aşınma direncini arttırdığı gözlenmiștir. Benzer şekilde, artan nanopartikül takviyesiyle, eğilme testi sonuçlarında da gözle görülür artışın olduğu gözlenmiştir. Takviye partiküllerinin yapı içerisindeki dağılımını incelemek amacıyla numunelere EDX analizi ile elementel dağlım analizi yapılmıştır. Elde edilen sonuçlar literatür ile karşılaştırılarak değerlendirilmiştir.

\section{Investigation of Mechanical Properties of Al-Nano SiC Composite Produced by Hot Pressing}

\section{Keywords}

Nano SiC,

Composite,

Hot pressing,

Sintering

\begin{abstract}
In this study, nano SiC particles with different ratios of $0.25,0.5$ and 1 $\mathrm{wt} \%$ were added to the pure $\mathrm{Al}$, and then the powder mixtures were subjected to mechanical alloying and sintering by hot press. After sintering process, samples were metallographically prepared for wear and bending tests. The results showed that the addition of a certain amount of nano SiC particles increased the wear resistance of pure Al matrix. The similar results were obtained after bending test results. In order to study the distribution of reinforcement particles in the structure, elemental distribution analysis was performed with EDX analysis. The results were evaluated in detail.
\end{abstract}

\section{Giriş}

Son 20 yıl dikkate alındığında; havacılık, otomotiv ve savunma sanayinde metal matrisli kompozitlerin (MMK) öneminin giderek arttı̆̆ gözlenmektedir. Bu tür malzemelerin en ilgi çekici yanları hafiflik, yüksek dayanım, uzun yorulma ömrü ve ısıl kararlılık olarak sıralanabilir. Metal matrisli kompozitler metal bir matris ve bu matris içerisine dağılmış (genellikle seramik) takviye fazından oluşmaktadır. Genellikle metal matris içerisine ilave edilen takviye fazı mikrometre ölçüsündedir. Ancak bu durum sünekliği çok fazla düşürdüğünden son dönemde yapılan çalışmalar matris fazı içerisine nano boyutlu takviye malzemelerinin ilavesi üzerine yoğunlaşmıştır $[1,2]$. Metal matrisli kompozitlerde en çok kullanılan matris fazları, çoğunlukla Al, Ti ve Mg gibi hafif metallerden oluşmaktadır. Bu elementler arasında da Al alaşımları sahip oldukları düşük yoğunluk, yüksek mekanik özellik, yüksek korozyon direnci ve düşük maliyet gibi özelliklerinden dolayı kullanımına en çok başvurulan matris fazı olarak kabul edilmektedir [3]. Matris fazı içerisine ilave edilen takviye fazları ise fiber veya partikül şeklinde olabilmektedir. Partikül takviyesi, matris fazı içerisinde dağılımının daha kontrollü ve daha kolay olması sebebiyle fiber takviyesine göre daha fazla tercih edilir. Özellikle SiC partikül takviyesi düşük maliyet, yüksek elastisite modülü, yüksek aşınma direnci ve yüksek sıcaklıklarda sergilediği üstün mekanik özellikler ile en çok tercih edilen partikül takviyelerinden biridir $[4,5]$.

Metal matrisli kompozitlerin üretiminde genellikle döküm ve toz metalurjisi yöntemi kullanılmaktadır [6]. Ancak döküm yöntemi açısından bakıldığında, partikül boyutunun küçülmesi sonucu yüzey gerilimindeki artış bazı problemlere neden 
olmaktadır. Sıvı metal-partikül arasında düşük ıslatma kabiliyetinden dolayı üretim prosesi zorlaşır $[1,3]$. Toz metalurjik üretim yönteminin karmaşık şekilli parçaların kolay üretimi, düşük enerji gerekliliği ve nihai şekle yakın parça üretimi gibi birçok avantajı vardır. Bu sebeple sinterleme işlemi seri üretimde en ekonomik üretim yöntemlerinden biri olarak kabul edilmektedir [7]. Özellikle Al matrisli kompozit malzemelerin üretiminde toz metalurjisi yöntemi, diğer yöntemlere göre daha üstün mekanik özellikler ortaya koymaktadır [8].

$\mathrm{Bu}$ çalışmada da $\mathrm{Al}$ matris içerisine nano $\mathrm{SiC}$ partikülleri ilave edilmiş, ardından toz metalurjik işlemlerden mekanik alaşımlama ve sıcak pres ile sinterleme işlemine tabi tutulmuştur.

\section{Materyal ve Metot}

$\mathrm{Bu}$ çalışmada toz formunda saf $\mathrm{Al}$ içerisine ağırlıkça $\% 0.25,0.5$ ve 1 oranlarında nano $\mathrm{SiC}(60 \mathrm{~nm})$ ilave edilmiş, ardından toz karışımları bilyeli değirmen içerisinde mekanik alaşımlama işlemine tabi tutulmuştur. Alaşımlama işlemi, $8 \mathrm{~mm}$ çapında zirkonya bilyeler kullanılarak 5 saat süre ile uygulamıştır. Cihaz, yapı içerisinde ısınmayı önlemek amaciyla her saatte bir yarım saat bekleme yapacak şekilde ayarlanmıştır. Alaşımlama sonrası elde edilen toz karışımları sıcak pres ile sinterleme işlemine tabi tutulmuştur. Sinterleme çevrimi Şekil 1'de gösterildiği gibi $600^{\circ} \mathrm{C}$ 'de 30 dakika olarak tayin edilmiştir. Isıtma ve soğutma süreleri ise 10 'ar dakika olarak uygulanmıştır.

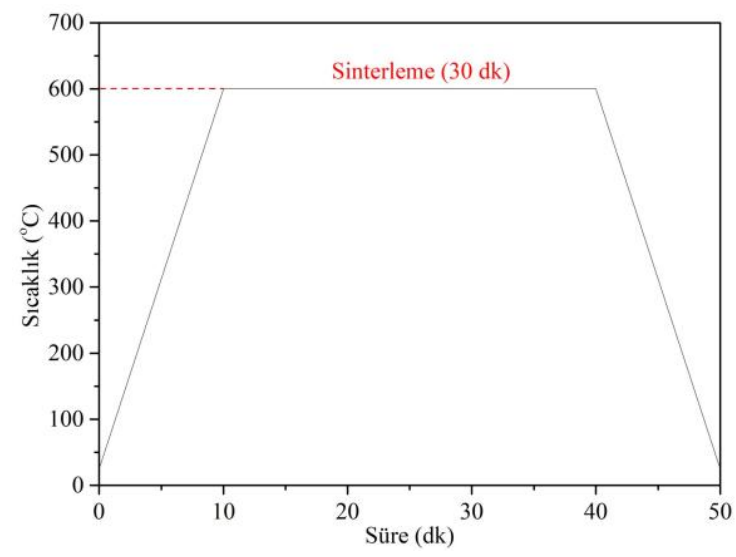

Şekil 1.Sinterleme çevrimi

Sıcak pres işlemi ardından $20 \mathrm{~mm}$ çapında ve $5 \mathrm{~mm}$ kalınlığında numuneler elde edilmiştir. Bu numuneler sırasıyla 600, 1000 ve 2000 gridlik zımparalar ile zımparalanmış ve kuru sürtünme aşınma işlemine tabi tutulmuştur. Aşınma işlemi 150 rpm'de, $250 \mathrm{~m}$ mesafe ve $5 \mathrm{~N}$ yük altında yapılmıștır. Așınma izleri SEM ile karakterize edilmiştir. Numuneler aynı zamanda 3 nokta-eğilme testine tabi tutulmuş ve test sonrası elde edilen eğilme mukavemeti-yer değiştirme grafikleri elde edilmiştir.

\section{Bulgular}

Metal matrisli seramik partikül takviyeli kompozit üretimi sürecinde karşılaşlan en önemli problemler yüksek yüzey alanına sahip nano partiküllerin topaklanması ve matris fazı içerisinde homojen bir şekilde dağıtılamamalarıdır. $\mathrm{Bu}$ tarz problemlerin önlenmesine yönelik uygulanan en önemli proseslerden birisi de toz metalurjik mekanik alașımlamadır. $\mathrm{Bu}$ sayede sert bilyelerin mekanik etkilerine sürekli maruz kalan metal ve seramik partikülleri homojen bir şekilde dağılım gösteren karışımların oluşumuna müsaade etmektedir.
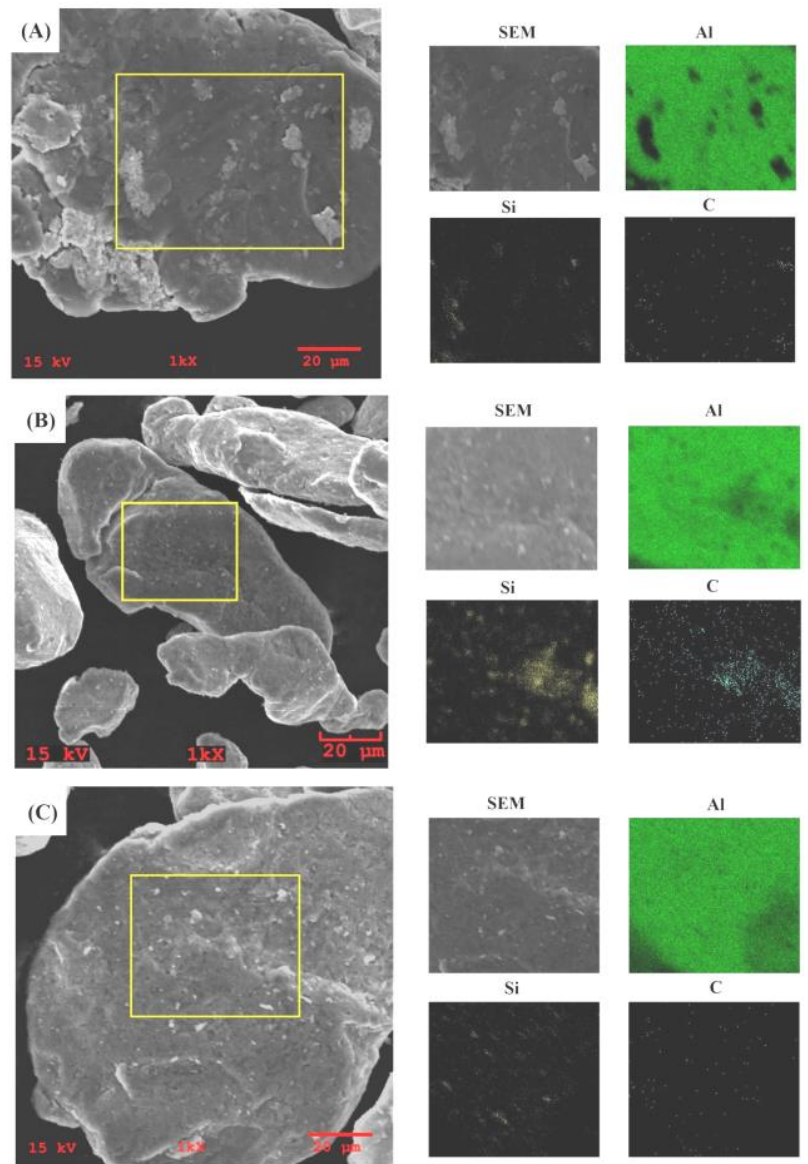

Şekil 2.(a) Al-0.25 nano SiC, (b) Al-0.5 nano SiC ve (c)Al-1 nano $\mathrm{SiC}$ (5) toz karışımlarına ait SEM görüntüsü ve elementel dağılım analizi

Alüminyum sahip olduğu yüksek süneklik özelliğinden dolayı, bilyalar ile etkileşim sürecinde deforme olacak, yeni yüzeyler oluşacak ve sistemde bulunan SiC partikülleri yeni oluşan yüzeylere tutunacak ve bu işlem proses boyunca sürekli devam edecektir. Alaşımlama sonrası elde edilen toz karışımlarının SEM görüntüleri ve elementel dağılım analizleri Şekil 2'de gösterilmiştir. Al partikülü üzerinde $\mathrm{SiC}$ nanopartikülleri homojen bir şekilde dağılmıștır. Bu sebeple, yapılan karıștırma işleminin yeterli olduğu söylenebilir.

Sinterlenmiş nano $\mathrm{SiC}$ takviyeli $\mathrm{Al}$ numunelerine uygulanan ball-on disc aşınma testinden sonra ortaya çıkan așınma oranları Șekil 3'te gösterilmiștir. Saf Al'a 
yapılan \% 0.25 nano $\mathrm{SiC}$ takviyesi, referans numuneye göre aşınma oranında bir düşüşe sebep olmuştur. \% 0.5 nano $\mathrm{SiC}$ takviyeli numune ise en düşük aşınma oranına sahip olan numune olmuştur. Daha fazla miktarda yapılan nano SiC takviyesinde ise (\%1) aşınma oranı ani bir artış göstererek matris malzemesinden de yüksek aşınma özelliği sergilemiştir. Böylelikle optimum aşınma şartlarının \% 0.5 takviyeli numunede oluştuğu söylenebilir. Murthy, yaptığı çalışmada karıştırmalı döküm yöntemini kullanarak Al AA2219 matris malzemesi içerisine \% 0.5, 1, 1.5 ve 2 oranlarında nano SiC ilave etmiş ve artan nanopartikül oranıyla spesifik aşınma oranında sürekli düşme olduğunu gözlemlemiştir [9]. Benzer şekilde Padmavathi ve Ramakrishman, çalışmalarında Al6061 alaşımına \% 0.5, 1 ve 1.5 oranlarında nano $\mathrm{SiC}$ takviye etmişler ve artan $\mathrm{SiC}$ oranıyla aşınma oranında azalma kaydetmişlerdir [10]. Bu çalışmada ise \%0.5 nano SiC ilavesinden sonra aşınma oranındaki artışın, nanopartiküllerin topaklanmalarının ve matris ile partiküller arasındaki bağlantının zayıflamasının bir sonucu olduğu düşünülmektedir.

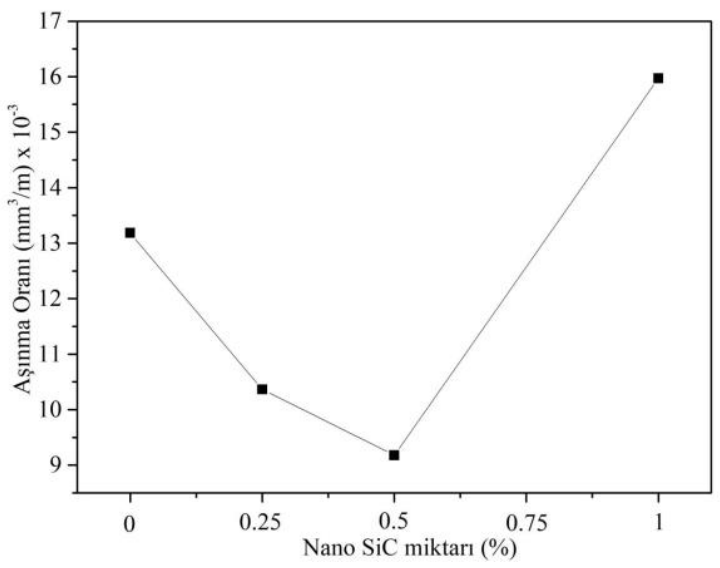

Şekil 3.Nano SiC takviyesi ile aşınma oranındaki değişim

Aşınma sonrası elde edilen yüzeylerin SEM görüntüleri Şekil 4'te gösterilmiştir. Şekil 4a saf Al'a ait aşınma yüzeyini göstermektedir. Alüminyumun sahip olduğu yüksek sünekliğin sonucu olarak aşınma yüzeyinde yoğun deformasyon izleri görülmektedir. \% 0.25 nano SiC takviye ilaveli numunede (Şekil $4 \mathrm{~b}$ ) ise nispeten daha az deformasyon etkisi görülmektedir. En düşük aşınma oranına sahip numunenin yüzey görüntüsü ise diğer yüzeylere göre daha pürüzsüz bir yüzeye sahiptir (Şekil 4c). Deformasyon etkisinin çok düştüğü ve buna bağlı olarak da aşınma oranının azaldığı görülmektedir. Şekil 4d ise şiddetli delaminasyon sonucu yüzeyden oldukça fazla miktarda malzeme kaybının olduğu ve aşınma oranının en yüksek değerini verdiği net bir şekilde görülebilir.

Şekil 5'te 3 nokta eğilme testine tabi tutulan numunelerden elde edilen eğilme mukavemeti-yer değiştirme grafiği verilmiştir. Aşınma sonuçlarına benzer şekilde saf Al'a yapılan nano partikül takviyesinin eğilme mukavemetini arttırdığ
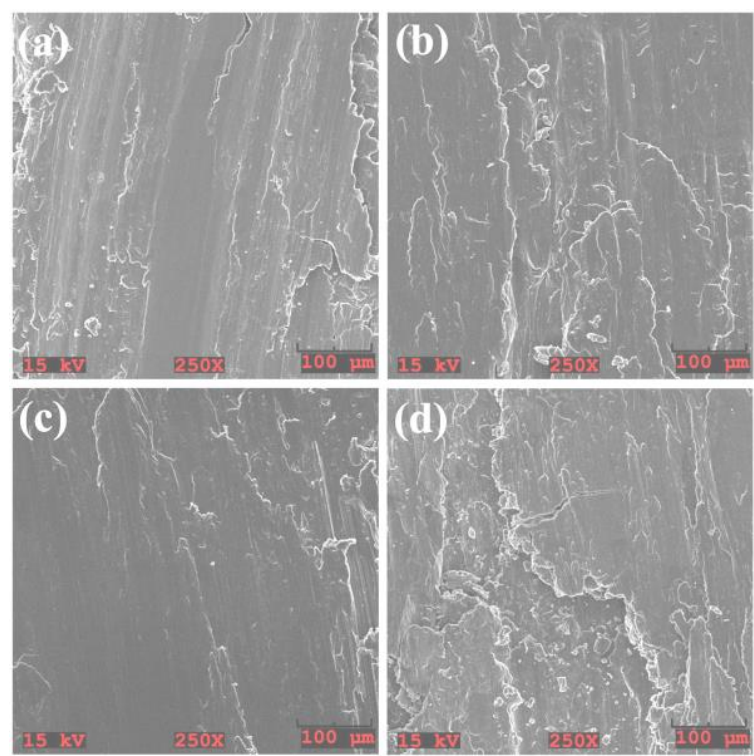

Şekil 4.(a) Saf Al, (b) Al-0.25 nano SiC, (c) Al- 0.5 nano SiC ve (d) Al-1 nano $\mathrm{SiC}$ aşınma yüzeylerinin SEM görüntüleri

gözlenmiştir. Saf Al'un sergilediği eğilme mukavemeti yaklaşık $200 \mathrm{MPa}$ iken \% 0.25 nano SiC takviyesi ile eğilme mukavemetinde 50 MPa'lık bir artış gözlenmiştir. \% 0.5 ve 1 nano SiC takviyeli numuneler ise çok az bir farkla, neredeyse benzer bir eğilme mukavemeti-yer değiştirme eğrisi sergilemiştir. $\mathrm{Bu}$ iki numune arasında benzer eğilme davranışı gözlenmiş ancak aşınma oranlarında önemli bir fark oluşmuştur.

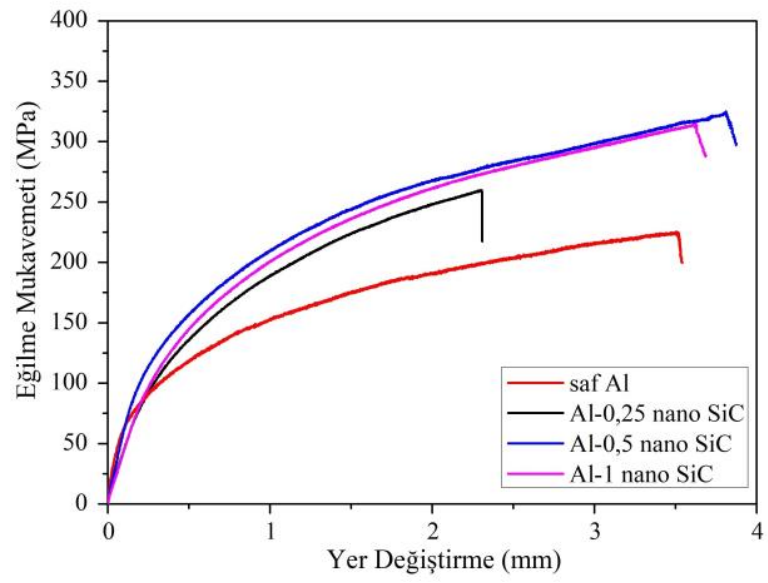

Şekil 5.Artan nanoSiC miktarı ile eğilme dayanımındaki değişim

\section{Tartışma ve Sonuç}

Metal matrisli nanopartikül takviyeli kompozit malzemelerde karşılaşılan en büyük problem, daha önce de bahsedildiği gibi, yüksek yüzey enerjisine sahip nanopartikül takviye fazının matris fazı içerisinde homojen dağıtılamaması sonucu kümeleşerek mekanik özelliklerde kötüleşmeye sebebiyet vermesidir. $\mathrm{Bu}$ sebeple bu çalışmada homojen karışım elde edilene kadar, öncelikli bir alaşımlama süresi optimizasyonu yapılmıştır. Uygun alaşımlama süresi tespit edildikten sonra yapının da homojen dağılıma sahip olduğu gözlenmiştir. 
Farklı nanopartikül takviyeli numunelerden en yüksek aşınma direncine sahip olan 0.5 nano $\mathrm{SiC}$ takviyeli numune olmuştur. $\mathrm{Bu}$ sonuç aşınma izlerinden elde edilen SEM görüntüleri ile de desteklenmiştir. Benzer bir sonuç 3 nokta eğilme testinde de gözlenmiştir. 0.5 nano $\mathrm{SiC}$ takviyeli numune en yüksek eğilme mukavemeti değerine ( 350MPa) ulaşmıştır.

\section{Teşekkür}

$\mathrm{Bu}$ çalıșma Kocaeli Üniversitesi Bilimsel Araștırma Projeleri Birimi tarafından desteklenmiştir.

\section{Kaynakça}

[1] Yang, Y.,Lan, J., Li, X. 2004. Study on bulk aluminum matrix nano-composite fabricated by ultrasonic dispersion of nano-sized SiC particles in molten aluminum alloy. Materials Scence and Enginerring: A, 380(1), 378-383.

[2] Yamanoglu, R. 2013. Effect of heat treatment on the tribological properties of $\mathrm{Al}-\mathrm{Cu}-\mathrm{Mg} /$ nanoSiC composites. Materials \& Design, 49, 820-825.

[3] Amouri, K. 2016. Microstructure and mechanical properties of Al-nano/micro $\mathrm{SiC}$ composites produced by stir casting technique. Materials Science and Engineering: A, 674, 569-578.

[4] Li, C. P., Wang, Z. G., Wang, H., Zhu, X. 2016. Fabrication of nano-SiC particulate reinforced Mg-8Al-1Sn composite by powder metallurgy combined with hot extrusion. Journal of
Materials Engineering and Performance, 25(11), 5049-5054.

[5] Yamanoglu, R., Zeren, M., German, R. M. 2012. Solidifaction characteristics of atomized AlCu4Mg1-SiC cimposite powders. Journal of Mining and Metallurgy B: Metallurgy, 48(1), 7379.

[6] Nassar, A. E., Nassar, E. E. 2017. Properties of aluminum matrix nano composites prepared by powder metallurgy processing. Hournal of King Saud University-Engineering Sciences, 29(3), 295-299.

[7] Tavakol, M. Mahnama, M., Naghdabadi, R. 2016. Shock wave sintering of $\mathrm{Al} / \mathrm{SiC}$ metal matrix nano-composites: A molecular Dynamics study. Computational Materials Science, 125, 255-262.

[8] Abdullahi, K., Al-Aqeeli, N. 2014. Mechanical alloying and spark plasma sintering of nano-SiC reinforced Al-12Si-0.3Mg alloy. Arabian Journal for Sicence and Engineering, 39(4), 3161-3168.

[9] Murthy, N. V. 2016. Preparation of SiC based aluminium metal matrix nano composites by high intensity ultrasonic cavitation process and evaluation of mechanical and tribological properties. IOP Conference Series: Materials Science and Engineering, 149(1), 012106.

[10] Padmavathi, K. R., Ramakrishman, R. 2017. Tribological properties of micro and nano $\mathrm{SiC}$ reinforced aluminium metal matrix composites. International Journal of ChemTech Research, $10(6), 367-372$. 